\title{
Silicon Nitride Stress Liner Impacts on the Electrical Characteristics of AlGaN/GaN HEMTs
}

\author{
Wei-Chih Cheng, ${ }^{1,2}$ Tao Fang, ${ }^{1}$ Siqi Lei, ${ }^{1}$ Yunlong Zhao, ${ }^{3}$ Minghao He, ${ }^{1}$ Mansun Chan, ${ }^{2}$ \\ Guangrui (Maggie) Xia, ${ }^{3}$ Feng Zhao, ${ }^{4}$ and Hongyu $\mathrm{Yu}^{1,5,6}$ \\ ${ }^{1}$ SUSTech School of Microelectronics, Southern University of Science and Technology, Shenzhen, China \\ ${ }^{2}$ Department of Electronic and Computer Engineering, Hong Kong University of Science and Technology, Hong Kong, China \\ ${ }^{3}$ Department of Materials Engineering, The University of British Columbia, Vancouver, BC, Canada \\ ${ }^{4}$ School of Engineering and Computer Science, Washington State University, Vancouver, WA, USA \\ ${ }^{5}$ Shenzhen Key Laboratory of the Third Generation Semi-conductor, Shenzhen, Guangdong, China \\ ${ }^{6}$ GaN Device Engineering Technology Research Center of Guangdong, Shenzhen, Guangdong, China \\ E-mail: yuhy@sustc.edu.cn
}

\begin{abstract}
Due to the piezoelectric nature of GaN, the 2DEG in AIGaN/GaN HEMT could be engineered by strain. In this work, $\mathrm{SiN}_{\mathrm{x}}$ deposited using dual-frequency PECVD was used as a stressor. The output performance of the devices was dominated by the surface passivation instead of the stress effect. However, the threshold voltage was increased by the induced stress, supporting strain engineering as an effective approach to pursue the normally-off operation of AIGaN/GaN HEMTs.
\end{abstract}

Keywords—gallium nitride (GaN), high electron mobility transistor (HEMT), strain engineering

\section{INTRODUCTION (HEADING 1)}

GaN-based high electron mobility transistors (HEMTs) have emerged as one of the key device options for next generation power electronics and high frequency applications. The wide bandgap provides the ability to support high electric fields. Meanwhile, a high on-current $\left(I_{o n}\right)$ can be achieved due to the high saturation speed of electrons in $\mathrm{GaN}$ and the presence of two-dimensional electron gas (2DEG) at the $\mathrm{AlGaN} / \mathrm{GaN}$ heterojunction.

One of the main reasons of forming 2DEG at the AlGaN/GaN heterojunction is the piezoelectric property of $\mathrm{GaN}$. The lattice-mismatch stress between $\mathrm{AlGaN}$ and GaN can generate a net internal electric field in the $\mathrm{AlGaN}$ barrier, which drives electrons to accumulate in the quantum well near the heterojunction [1]. Due to the piezoelectric nature of $\mathrm{GaN}$, the 2DEG concentration and thus the electrical characteristics of the AlGaN/GaN HEMT can be modulated by applying strain [2-3]. Besides, simulation results showed that the strain provided by the passivation layer can induce significant amount of piezoelectric charges in the submicron gate region [3]. Therefore, strain engineering is believed to be an effective approach to adjust the threshold voltage $\left(V_{t h}\right)$ of an $\mathrm{AlGaN} / \mathrm{GaN}$ HEMT with a scaled gate length.

In our previous work, AlGaN/GaN HEMTs with micron gate lengths (micron devices) were prepared, and $\mathrm{SiN}_{\mathrm{x}}$ stressors with different intrinsic stresses were deposited on the devices by dual-frequency plasma-enhanced chemical vapor deposition (PECVD) [4]. Additional stress in AlGaN layer was observed using Raman spectroscopy [4]. However, surface damages caused by the deposition process was believed to dominate the output performance change. The results will be reviewed in sec. II. Besides, devices with submicron gate lengths (submicron devices) and different strain $\mathrm{SiN}_{\mathrm{x}}$ were further investigated. Also, we used compressive strain in the 2DEG region underneath the gate to achieve a $V_{t h}$ increase of approximately one volt in a device with a $\mathrm{L}_{\mathrm{g}}=$ $100 \mathrm{~nm}$, giving an alternative way to pursue normally-off devices for RF applications.

\section{IMPACTS FROM SINX STRESSORS ON MICRON ALGAN/GAN HEMTS}

The structure of the AlGaN/GaN HEMT in this work is shown in Fig. 1. The strain was provided by the $\operatorname{SiN}_{x}$ passivation layer deposited by PECVD with dual plasma excitation frequencies. By varying the duty cycles of the high and low plasma excitation frequencies throughout the deposition process, the strain of the deposited $\mathrm{SiN}_{\mathrm{x}}$ could be engineered [5]. Three sets of frequency duty cycle parameters were used in this work, corresponding to tensile, compressive, and unstrained $\mathrm{SiN}_{\mathrm{x}}$, respectively. The setting details were explained in Ref. [4].

The on-resistance $\left(R_{o n}\right)$ of the devices with different $\mathrm{SiN}_{\mathrm{x}}$ stresses are summarized in Table I with the 2DEG sheet resistance extracted by the transmission line model $\left(R_{\square, 2 D E G}\right)$. The tensile $\operatorname{SiN}_{\mathrm{x}}$ was expected to introduce an additional compression to $\mathrm{AlGaN}$ and lead to the increased $R_{\text {on }}$ and $R_{\square, 2 D E G}$. However, the opposite behavior was observed. To investigate this problem, Raman spectroscopy was used to measure the stress in the $\mathrm{AlGaN}$ and $\mathrm{GaN}$ layers.

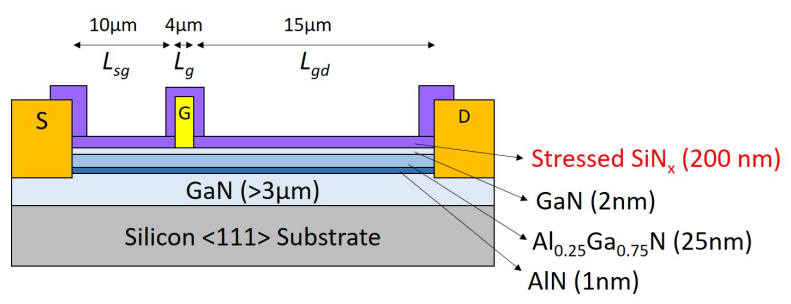

Fig. 1. The device structure of AlGaN/GaN HEMT with the gate length $\left(L_{g}\right)$, source-to-gate length $\left(L_{s g},\right)$ and gate-todrain length $\left(L_{g d}\right)$ labelled.

TABle I. ChanNel Resistances of Micron Devices

\begin{tabular}{|l|c|c|}
\hline \multicolumn{1}{|c|}{$\mathbf{S i N}_{\mathbf{x}}$} & $\boldsymbol{R}_{\square, 2 D E G}(\boldsymbol{\Omega})$ & $\boldsymbol{R}_{\boldsymbol{o n}}(\boldsymbol{\Omega}-\mathbf{m m})$ \\
\hline Compressive & 1082 & 32 \\
\hline Unstrained & 356 & 12 \\
\hline Tensile & 299 & 11 \\
\hline
\end{tabular}




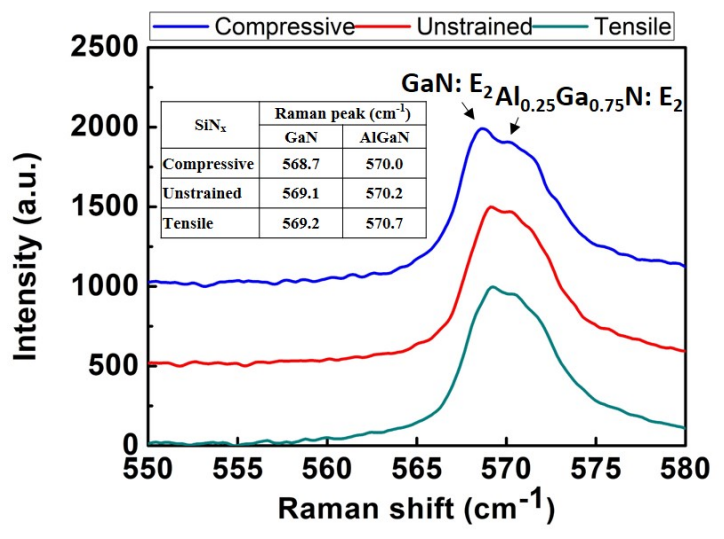

Fig. 2. Raman spectra of $\mathrm{AlGaN} / \mathrm{GaN}$ heterostructure with different strains of $\mathrm{SiN}_{\mathrm{x}}$. The AlGaN peak shifted toward a higher frequency due to the compressive strain induced in AlGaN by the tensile $\mathrm{SiN}_{\mathrm{x}}$ on the surface.

The $E_{2}$ phonon frequency decreases with tensile stresses [6]. In this study, the access regions of devices (between gate and drain) with different stressed $\mathrm{SiN}_{\mathrm{x}}$ were probed with a 442-nm laser, and each Raman spectrum showed a GaN peak (near $569 \mathrm{~cm}^{-1}$ ) and an AlGaN peak (near $570.5 \mathrm{~cm}^{-1}$ ), as shown in Fig. 2. The AlGaN peak of the sample with tensile $\mathrm{SiN}_{\mathrm{x}}$ appeared at a higher frequency than the other samples, suggesting that additional compression was generated in the AlGaN layer. That translates to an increased $R_{o n}$ and $R_{\square, 2 D E G}$. Therefore, the experimental results showing a decreased $R_{o n}$ and $R_{\square, 2 D E G}$ could not be explained by the stress effect.

Another reason to explain the experimental observations is the surface passivation quality. The compressive PECVD $\mathrm{SiN}_{\mathrm{x}}$ was prepared using longer period of low-frequency plasma excitation, which may cause more damages to the AlGaN surface by nitrogen ion bombardment [7]. As a result, the higher off current $\left(I_{o f f}\right)$ and lower $I_{o n}$ were observed in the device with compressive $\mathrm{SiN}_{\mathrm{x}}$, as shown in Fig. 3. In contrast, the tensile $\mathrm{SiN}_{\mathrm{x}}$ was deposited using high-frequency plasma excitation throughout the deposition, which should have less ion bombardment and a better passivation quality to AlGaN. Therefore, the device with tensile $\mathrm{SiN}_{\mathrm{x}}$ can reach the lower $R_{o n}$ and $R_{\square, 2 D E G}$, even though the additional compression was introduced to $\mathrm{AlGaN}$.

In summary, the strain and the surface quality effects from the $\mathrm{SiN}_{\mathrm{x}}$ stressors are two competing effects. In this case, the output performance (especially $I_{\text {off }}$ ) of devices were dominated by the passivation quality instead of the stress of $\mathrm{SiN}_{\mathrm{x}}$. Besides output characteristics, a positive 0.3 -volt $V_{\text {th }}$ shift was observed when a compressive $\operatorname{SiN}_{\mathrm{x}}$ was applied on the devices with $L_{g}=4 \mu \mathrm{m}$. In the next section, the strain effect on the $V_{t h}$ of the device with different $L_{g}(0.1$ to $4 \mu \mathrm{m})$ will be explored

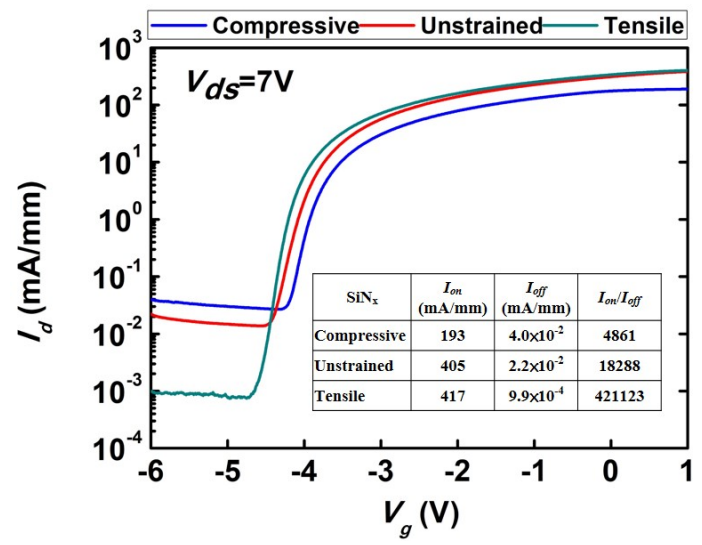

Fig. 3. Transfer characteristics of AlGaN/GaN HEMTs with different strain $\mathrm{SiN}_{\mathrm{x}}$. The device with compression $\mathrm{SiN}_{\mathrm{x}}$ showed a larger $I_{\text {off }}$ and a lower $I_{o n}$. The $I_{o n}, I_{\text {off }}$ are defined as the $I_{d}$ at $V_{g}=1$ and $-6 \mathrm{~V}$, respectively

\section{VTH INCREASE IN SUBMICRON ALGAN/GAN HEMTS FOR RF APPLICATION USING STRAIN ENGINEERING}

The device structure in the study is similar to that shown in Fig. 1, with $L_{g}$ from 0.1 to $4 \mu \mathrm{m}$, as shown in Table II. The submicron devices exhibited a reduced $R_{o n}$ upon application of the tensile $\mathrm{SiN}_{\mathrm{x}}$, consistent with the behavior observed in the micron devices.

The gate-length dependence of $V_{t h}$ voltage of devices with different stressed $\mathrm{SiN}_{\mathrm{x}}$ was drawn in Fig. 4, including the micron devices in Sec. II. Devices with unstrained $\mathrm{SiN}_{\mathrm{x}}$ exhibited a lower $V_{t h}$ when gate length was scaled more. The more negative $V_{\text {th }}$ of unstrained devices was due to shortchannel effects or gate-fringing effect [8]. In contrast, the devices with compressive $\mathrm{SiN}_{\mathrm{x}}$ exhibited a $V_{t h}$ increase when the gate length was scaled.

To investigate the gate length dependence of the induced stress underneath the gate region, the stress distributions were simulated using Silvaco. In the simulations, $\mathrm{SiN}_{\mathrm{x}}$ layers with $-1 \mathrm{GPa}$ intrinsic stress were applied to the devices with $L_{g}=0.1$ and $0.4 \mu \mathrm{m}$, as shown in Fig. 5. For devices with $L_{g}$ $=0.1 \mu \mathrm{m}$, more intense compression is produced at the edge of the gate. In addition, the compressive $\mathrm{SiN}_{\mathrm{X}}$ has a greater influence over the heterostructure under the gate region, while tensile stress exists in some regions of under the 0.4 $\mu \mathrm{m}$ gate. Because the smaller gate can be influenced more by the stressed $\mathrm{SiN}_{\mathrm{x}}$, the $V_{\text {th }}$ of devices increased when gate length was decreased.

TABLE II. DEVICE DimENSIONS

\begin{tabular}{|l|c|c|c|}
\hline Device type & $\boldsymbol{L}_{g}(\boldsymbol{\mu m})$ & $\boldsymbol{L}_{s g}(\boldsymbol{\mu m})$ & $\boldsymbol{L}_{g d}(\boldsymbol{\mu m})$ \\
\hline \multirow{3}{*}{ Submicron device } & 0.1 & 3.7 & 6.3 \\
\cline { 2 - 4 } & 0.2 & 3.7 & 6.3 \\
\cline { 2 - 4 } & 0.4 & 3.7 & 6.3 \\
\cline { 2 - 4 } & 0.4 & 3.7 & 10.3 \\
\hline Micron device & 4 & 10 & 15 \\
\hline
\end{tabular}




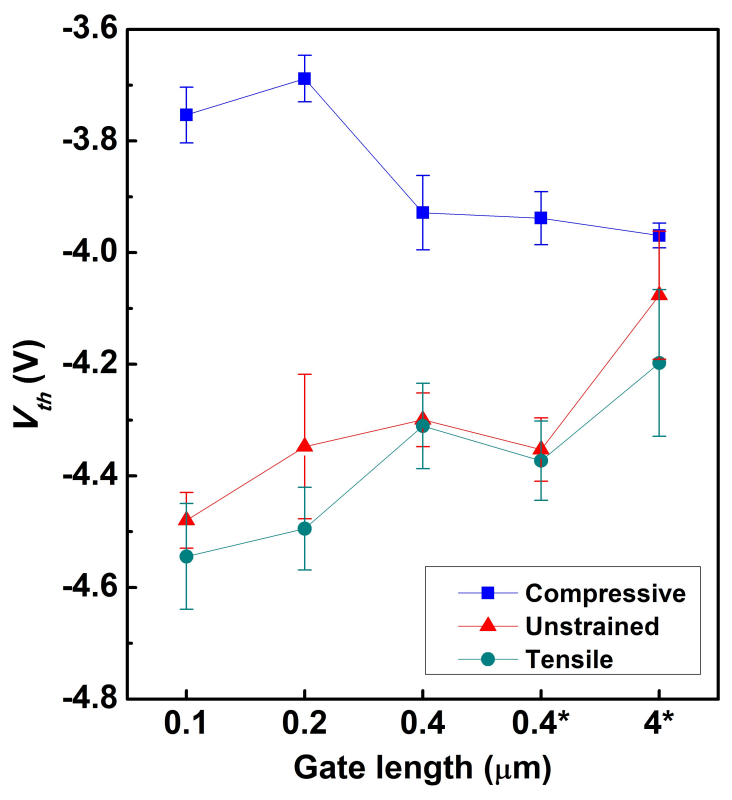

Fig. 4. Gate-length dependence of the $V_{t h}$ of the devices with different stressed $\mathrm{SiN}_{\mathrm{x}}$. The error bars are also showed, representing the standard deviation out of the data point.

According to the stress simulation results (Fig. 5), induced stress underneath the gate is larger for smaller $L_{g}$. Compressive stressors introduce compressive in-plane stresses in $\mathrm{AlGaN}$ underneath the gate, which causes a smaller amount of piezoelectric charges in $\mathrm{AlGaN}$, depleting the 2DEG under the metal gate. As a result, even if the short channel effect had an influence, a submicron device with a compressive $\mathrm{SiN}_{\mathrm{x}}$ liner could achieve a higher $V_{t h}$.

In summary, for these devices with different $L_{g}$, the $V_{t h}$ dependence can come from two sources: the short-channel effect and the stress effect. The experimental data support that the stress effect is the dominant effect.
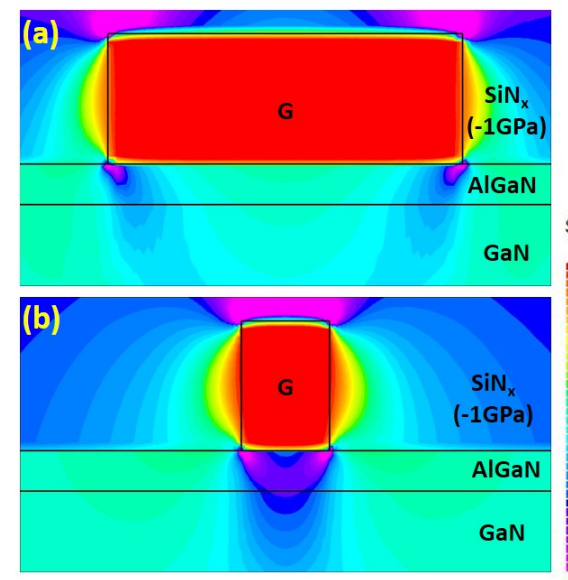

Stress $X X$ (dyne/cm2)

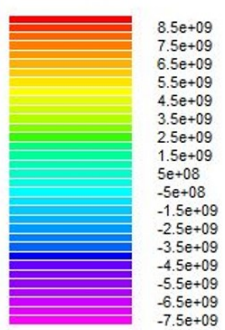

Fig. 5. Simulated stress distributions in the devices with 1GPa compressive $\mathrm{SiN}_{\mathrm{x}}$ liner. (a) $L_{g}=0.1 \mu \mathrm{m}$ and (b) $L_{g}=$ $0.4 \mu \mathrm{m}$. In the device with $0.1 \mu \mathrm{m}$ gate length, more intensive compression is developed at the gate edge. There are more compressive stresses in the $\mathrm{AlGaN} / \mathrm{GaN}$ region underneath the gate.
For RF application, normally-off operation is preferred. An etching process, which is necessary to prepare enhancement-mode device, such as MIS-HEMT and P-GaN HEMT, is undesired for high frequency application [9]. The fact that the $V_{t h}$ of scaled devices can be adjusted by strain engineering without an etch step provides a useful approach for pursing enhancement-mode AlGaN/GaN HEMT.

\section{CONCLUSION}

Due to the piezoelectric nature of GaN, the 2DEG in $\mathrm{AlGaN} / \mathrm{GaN}$ HEMT could be engineered by stressed $\mathrm{SiN}_{\mathrm{x}}$. The output performance $\left(I_{o n}\right.$ and $\left.R_{o n}\right)$ of the devices was dominated by the surface passivation instead of the stress effect. However, the $V_{\text {th }}$ could be increased by the induced stress. It was increased by approximately $1 \mathrm{~V}$ with a compressive $\mathrm{SiN}_{\mathrm{x}}$ liner for devices with $L_{g}=0.1 \mu \mathrm{m}$. This finding supports that strain engineering is an effective approach pursuing enhancement-mode AlGaN/GaN HEMTs.

\section{ACKNOWLEDGMENT}

This work was supported by the projects with grant number 2017A050506002, JCYJ20160226192639004, and JCYJ20170412153356899. Device fabrication was performed at Materials Characterization and Preparation Center, Southern University of Science and Technology with equipment supported with various grants.

\section{REFERENCES}

[1] R. J. Trew, G. L. Bilbro, W. Kuang, Y. Liu, and H. Yin. "Microwave AlGaN/GaN HFETs." IEEE Microwave Magazine, vol. 6, no. 1, pp. 56-66. 2005.

[2] N. Shigekawa and S. Sugitani. "Analysis of passivation-film-induced stress effects on electrical properties in AlGaN/GaN HEMTs." IEICE Trans. Electron., vol. 93, no. 8, pp. 1212-1217. 2010.

[3] S. Shervin, S. Kim, M. Asadirad, S. Ravipati, K. Lee, K. Bulashevich, and J. Ryou. "Strain-effect transistors: Theoretical study on the effects of external strain on III-nitride high-electron-mobility transistors on flexible substrates." Appl. Phys. Lett., vol. 107, no. 19 , pp. 193504. 2015 .

[4] W. Cheng, S. Lei, W. Li, F. Zhao, M. Chan, and H. Yu, " Improving the drive current of AlGaN/GaN HEMT using external strain engineering," in 2019 IEEE Electron Devices Technology and Manufacturing Conference (EDTM), in press.

[5] W. S. Tan, P. A. Houston, G. Hill, R. J. Airey, and P. J. Parbook. "Influence of dual-frequency plasma-enhanced chemical-vapor deposition $\mathrm{Si}_{3} \mathrm{~N}_{4}$ passivation on the electrical characteristics of AlGaN/GaN heterostructure field-effect transistors." J Electron Mater, vol. 33, no. 5, pp. 400-407. 2004.

[6] M. Kuball. "Raman spectroscopy of GaN, AlGaN and AlN for process and growth monitoring/control." Surface and Interface Analysis: An International Journal devoted to the development and application of techniques for the analysis of surfaces, interfaces and thin films, vol. 31, no. 10 , pp. 987-999. 2001

[7] W. S. Tan, P. A. Houston, G. Hill, R. J. Airey, and P. J. Parbook. "Influence of dual-frequency plasma-enhanced chemical-vapor deposition $\mathrm{Si}_{3} \mathrm{~N}_{4}$ passivation on the electrical characteristics of $\mathrm{AlGaN} / \mathrm{GaN}$ heterostructure field-effect transistors." J Electron Mater, vol. 33, no. 5 , pp. 400-407. 2004.

[8] T. Ide, M. Shimizu, A. Nakajima, M. Inada, S. Yagi, G. Piao, Y. Yano, N. Akutsu, H. Okumura, and K. Arai. "Gate-length dependence of DC characteristics in submicron-gate $\mathrm{AlGaN} / \mathrm{GaN}$ high electron mobility transistors." Japanese journal of applied physics, vol. 46, no. 4S , pp. 2334. 2007.

[9] R. Aubry, J. C. Jacquet, M. Oualli, O. Patard, S. Piotrowicz, E. Chartier, N. Michel, L. T. Xuan, D. Lancereau, and C. Potier. "ICPCVD SiN passivation for high-power RF InAlGaN/GaN/SiC HEMT." IEEE Electron Device Lett., vol. 37, no. 5 , pp. 629-632. 2016. 